\title{
Early Spironolactone Treatment Attenuates Heart Failure Development by Improving Myocardial Function and Reducing Fibrosis in Spontaneously Hypertensive Rats
}

\author{
Marcelo D.M. Cezara Ricardo L. Damatto ${ }^{a} \quad$ Luana U. Pagan ${ }^{a} \quad$ Aline R.R. Lima ${ }^{a}$

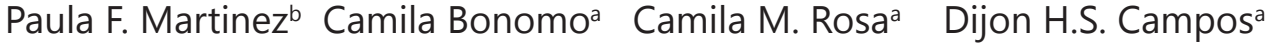 \\ Antonio C. Cicogna ${ }^{a}$ Mariana J. Gomes ${ }^{a}$ Silvio A. Oliveira-Jrb Daniella A. Blotta ${ }^{\mathrm{b}}$ \\ Marina P. Okoshi ${ }^{a}$ Katashi Okoshi ${ }^{a}$ \\ aDepartment of Internal Medicine, Botucatu Medical School, Sao Paulo State University, UNESP \\ Botucatu, bFederal University of Mato Grosso do Sul, Campo Grande, Brazil
}

\section{Key Words}

Aldosterone antagonist - Cardiac remodeling - Collagen - Ventricular function - Papillary muscle $\cdot$ Spontaneously hypertensive rat

\begin{abstract}
Background: We evaluated the role of the aldosterone blocker spironolactone in attenuating long-term pressure overload-induced cardiac remodeling and heart failure (HF) in spontaneously hypertensive rats (SHR). Methods and Results: Thirteen month-old male SHR were assigned to control (SHR-C, $\mathrm{n}=20$ ) or spironolactone (SHR-SPR, $20 \mathrm{mg} / \mathrm{kg} / \mathrm{day}, \mathrm{n}=24$ ) groups for six months. Normotensive Wistar-Kyoto rats $(\mathrm{WKY}, \mathrm{n}=15)$ were used as controls. Systolic blood pressure was higher in SHR groups and unchanged by spironolactone. Right ventricular hypertrophy, which characterizes HF in SHR, was less frequent in SHR-SPR than SHR-C. Echocardiographic parameters did not differ between SHR groups. Myocardial function was improved in SHR-SPR compared to SHR-C [developed tension: WKY 4.85 \pm 0.68 ; SHR-C $5.22 \pm 1.64$; SHR-SPR $6.80 \pm 1.49 \mathrm{~g} / \mathrm{mm}^{2}$; -dT/dt: WKY 18.0 (16.0-19.0); SHR-C 20.8 (18.4-25.1); SHR-SPR $\left.28.9(24.2-34.6) \mathrm{g} / \mathrm{mm}^{2} / \mathrm{s}\right]$. Cardiomyocyte cross-sectional area and total collagen concentration (WKY 1.06 \pm 0.34 ; SHR-C 1.85 \pm 0.63 ; SHR-SPR $1.28 \pm 0.39 \mu \mathrm{g} / \mathrm{mg}$ wet tissue) were greater in SHR-C than WKY and SHR-SPR. Type 3 collagen expression was lower in SHR-C than WKY and unchanged by spironolactone. Soluble collagen, type I collagen, and lysyl oxidase did not differ between groups. Conclusion: Early spironolactone treatment decreases heart failure development frequency by improving myocardial systolic and diastolic function and attenuating hypertrophy and fibrosis in spontaneously hypertensive rats.
\end{abstract}

Copyright $(2015$ S. Karger AG, Basel

Katashi Okoshi

KARGER 125
Departamento de Clinica Medica, Faculdade de Medicina de Botucatu, UNESP Rubiao Junior, S/N 18618-970 - Botucatu, SP, Brazil

Tel. + 55143880 1171, Fax + 55143882 2238, E-Mail katashi@fmb.unesp.br 


\section{Introduction}

Systemic arterial hypertension is a major cause of left ventricular hypertrophy and heart failure [1]. During long term pressure overload, stable cardiac hypertrophy develops and may progress to a decompensated state with left ventricular systolic and diastolic dysfunction and heart failure $[2,3]$.

Aldosterone, a mineralocorticoid hormone, mediates the renin-angiotensin-aldosterone system which is involved in several processes activated during pathological cardiac remodeling $[4,5]$. Experimental studies have shown that aldosterone induces deleterious cardiovascular effects such as myocardial fibrosis, myocyte hypertrophy and apoptosis, oxidative stress, electrical remodeling, vascular injury, endothelial dysfunction, renal retention of sodium and water, and sudden death [6-10]. Furthermore, the aldosterone blockers spironolactone and eplerenone can attenuate structural, functional, and molecular changes in several models of cardiac injury [11-15]. In clinical settings, mineralocorticoid receptor antagonists reduce mortality and/or morbidity in patients with systolic dysfunction post-myocardial infarction [16] and in patients with reduced left ventricular ejection fraction and heart failure in New York Heart Association functional classes II to IV [17-19]. On the other hand, aldosterone blockade failed to reduce the incidence of cardiovascular morbimortality [20] or improve maximal exercise capacity, symptoms, or quality of life [21] in heart failure patients with preserved ejection fraction.

The spontaneously hypertensive rat (SHR) is a widely used experimental model for studying left ventricular hypertrophy and heart failure $[2,22]$. It presents early arterial hypertension and left ventricular hypertrophy which evolves slowly to ventricular dysfunction and heart failure during maturity and senescence $[3,22,23]$. The transition from long-term compensated left ventricular hypertrophy to cardiac failure is characterized by marked myocardial fibrosis with an increase in collagen type I and collagen type I-to-III ratio $[2,24-27]$. The potential beneficial role of aldosterone blockers in preventing or attenuating pressure overload-induced cardiac remodeling and heart failure development has not yet been completely clarified. In a previous work we observed that administering spironolactone from 16 to 22 months of age despite reducing mortality did not change cardiac remodeling [23]. At this stage SHRs probably presented advanced myocardial fibrosis thus preventing a reverse remodeling process. In this study we evaluated the effects of early spironolactone administration on heart failure development, left ventricular and myocardial function, and cardiac fibrosis in spontaneously hypertensive rats.

\section{Materials and Methods}

\section{Experimental groups}

Male spontaneously hypertensive rats (SHR) were purchased from the Central Animal House at Botucatu Medical School, UNESP. All animals were housed in a room under temperature control at $23{ }^{\circ} \mathrm{C}$ and kept on a 12-hour light/dark cycle. Food and water were supplied ad libitum. All experiments and procedures were approved by Botucatu Medical School Ethics Committee, UNESP, Botucatu, SP, Brazil.

Thirteen-month-old SHR were assigned to control group (SHR-C, $n=20$ ) or spironolactone treatment (SHR-SPR, n=24). Spironolactone was added to rat chow at $20 \mathrm{mg} / \mathrm{kg} /$ day for six months. Age-matched normotensive Wistar-Kyoto rats were used as controls (WKY, n=15). Rats were weighed weekly to adjust drug dosage.

Systolic arterial pressure was measured by the tail-cuff method at the start and end of the experiment. During euthanasia, we evaluated pathological evidence of heart failure such as pulmonary congestion (lungsto-body weight ratio > 2 standard deviations above the mean for the WKY group) and right ventricular hypertrophy (right ventricle weight-to-body weight ratio $>0.8 \mathrm{mg} / \mathrm{g}$ ) [28, 29].

Echocardiographic study

Echocardiographic evaluation was performed using a commercially available echocardiograph (General Electric Medical Systems, Vivid S6, Tirat Carmel, Israel) equipped with a 5 - 11.5 MHz multifrequency probe 


\section{Cellular Physiology Cell Physiol Biochem 2015;36:1453-1466 \begin{tabular}{l|l|l}
\hline DOI: 10.1159/000430310 & (C)15 S. Karger AG, Basel
\end{tabular} and Biochemistry Publisnea onine. Juy uo, 2015

[30-32]. Rats were anesthetized by intramuscular injection of a mixture of ketamine $(50 \mathrm{mg} / \mathrm{kg})$ and xylazine $(0.5 \mathrm{mg} / \mathrm{kg})$. A two-dimensional parasternal short-axis view of the left ventricle (LV) was obtained at the level of the papillary muscles. M-mode tracings were obtained from short-axis views of the LV at or just below the tip of the mitral-valve leaflets, and at the level of the aortic valve and left atrium. M-mode images of the LV were printed on a black-and-white thermal printer (Sony UP-890MD) at a sweep speed of $100 \mathrm{~mm} / \mathrm{s}$. All LV structures were manually measured by the same observer according to the leading-edge method of the American Society of Echocardiography [33]. Measurements obtained were the mean of at least five cardiac cycles on the M-mode tracings. The following structural variables were measured: left atrium (LA) diameter, LV diastolic and systolic dimensions (LVDD and LVSD, respectively), LV diastolic posterior wall thickness (PWT), LV diastolic septal wall thickness (SWT), and aortic diameter (AO). Left ventricular mass (LVM) was calculated using the formula [(LVDD + PWT + SWT $\left.)^{3}-(\mathrm{LVDD})^{3}\right] \times 1.04$. Relative wall thickness (RWT) was calculated as $2 \times$ PWT/LVDD. LV function was assessed by the following parameters: endocardial fractional shortening (EFS), midwall fractional shortening (MWFS), ejection fraction (EF), posterior wall shortening velocity (PWSV), early and late diastolic mitral inflow velocities (E and A waves), and E/A ratio.

\section{Myocardial functional study}

Two days after final echocardiographic study, myocardial contractile performance was evaluated in isolated LV papillary muscle preparation as previously described $[34,35]$. The rats were anesthetized with pentobarbital sodium, $50 \mathrm{mg} / \mathrm{kg}$, intraperitoneally, and decapitated. Hearts were quickly removed and placed in oxygenated Krebs-Henseleit solution at $28^{\circ} \mathrm{C}$. LV anterior or posterior papillary muscle was dissected free, mounted between two spring clips, and placed vertically in a chamber containing KrebsHenseleit solution at $28{ }^{\circ} \mathrm{C}$ and oxygenated with a mixture of $95 \% \mathrm{O}_{2}$ and $5 \% \mathrm{CO}_{2}(\mathrm{pH} 7.38)$. The composition of the Krebs-Henseleit solution in mM was as follows: $118.5 \mathrm{NaCl}, 4.69 \mathrm{KCl}, 1.25 \mathrm{CaCl}_{2}, 1.16 \mathrm{MgSO}_{4}, 1.18$ $\mathrm{KH}_{2} \mathrm{PO}_{4}, 5.50$ glucose, and $25.88 \mathrm{NaHCO}_{3}$. The spring clips were attached to a Kyowa model 120T-20B force transducer and a lever system which allowed for muscle length adjustment. Preparations were stimulated 12 times/min at a voltage $10 \%$ above threshold.

After a 60-min period, during which the preparations were permitted to shorten whilst carrying light loads, muscles were loaded to contract isometrically and stretched to the apices of their length-tension curves $\left(\mathrm{L}_{\max }\right)$. After a 5-min period, during which preparations performed isotonic contractions, muscles were again placed under isometric conditions and length-tension curve apex determined. A 15-min period of stable isometric contraction was imposed prior to the experimental period. One isometric contraction was then recorded for later analysis.

The following parameters were measured from isometric contraction: peak of developed tension (DT, $\left.\mathrm{g} / \mathrm{mm}^{2}\right)$, resting tension $\left(\mathrm{RT}, \mathrm{g} / \mathrm{mm}^{2}\right)$, maximum rate of tension development $\left(+\mathrm{dT} / \mathrm{dt}, \mathrm{g} / \mathrm{mm}^{2} / \mathrm{s}\right)$, maximum rate of tension decline (-dT/dt, g/mm $\left./ \mathrm{mm}^{2} \mathrm{~s}\right)$, and time to peak of tension (TPT). To evaluate contractile reserve, mechanical papillary muscle performance was evaluated at basal condition and after the following inotropic stimulation: post-rest contraction, extracellular $\mathrm{Ca}^{2+}$ concentration increase, and $\beta$-adrenergic agonist isoproterenol addition to the nutrient solution [36].

Papillary muscle cross-sectional area (CSA) was calculated from muscle weight and length by assuming cylindrical uniformity and a specific gravity of 1.0. All force data were normalized for muscle CSA.

After dissecting papillary muscle, atria and ventricles were separated and weighed. Fragments of lung were weighed before and after drying sessions $\left(65^{\circ} \mathrm{C}\right.$ for $72 \mathrm{~h}$ ) to evaluate wet-to-dry weight ratio. The tibia was removed and dried. Atria and left and right ventricular weight was normalized to both body weight and tibia length.

\section{Morphologic study}

Transverse LV sections were fixed in $10 \%$ buffered formalin and embedded in paraffin. Five-micrometer thick sections were stained with hematoxylin eosin. At least 150 fiber cross-sectional areas were measured from each heart. Measurements were performed using a Leica microscope (magnification 40X) attached to a video camera and connected to a computer equipped with image analysis software (Image-Pro Plus 3.0, Media Cybernetics, Silver Spring, MD, USA) [37].

Myocardial collagen evaluation

Total and soluble myocardial collagen was assessed using two colorimetric assays (QuickZyme Collagen Assay, Leiden, Netherlands) according to manufacturer instructions. 


\section{Cellular Physiology Cell Physiol Biochem 2015;36:1453-1466 \begin{tabular}{l|l|l}
\hline DOI: 10.1159/000430310 & (C) 2015 S. Karger AG, Basel
\end{tabular}

Serum creatinine and electrolytes concentration

Sodium, potassium, and magnesium serum concentrations were analyzed by flame photometry (FC280, CELM) using a commercial standard solution. Creatinine concentration was quantified using the CELM SB-190 model spectrophotometer.

\section{Western blotting analysis}

Myocardial protein levels were analyzed by Western blotting according to a previously described method $[38,39]$ with specific type I collagen (anti-col1a1, C-18, sc-8784-r; Santa Cruz Biotechnology, Santa Cruz, CA, USA), type III collagen (anti-collagen III, FH-7A, ab6310; Abcam, Cambridge, UK), and lysyl oxidase (anti-LOX, 1 ab60178; Abcam) antibodies. Protein levels were normalized to those of GAPDH (6C5, sc-32233, Santa Cruz Biotechnology). Muscle protein was extracted using Tris-Triton buffer (10 mM Tris pH 7.4, $100 \mathrm{mM}$ NaCl, 1 mM EDTA, 1 mM EGTA, 1\% Triton X-100, 10\% glycerol, 0.1\% SDS, 0.5\% deoxycholate). Supernatant protein content was quantified by the Bradford method. Samples were separated on a polyacrylamide gel and then transferred to a nitrocellulose membrane [40, 41]. After blockage, the membrane was incubated with primary antibody. The membrane was washed with TBS and Tween 20 and incubated with secondary peroxidase-conjugated antibody. Super Signal ${ }^{\circledR}$ West Pico Chemiluminescent Substrate (Pierce Protein Research Products, Rockford, USA) was used to detect bound antibodies.

\section{Statistical analysis}

Data are expressed as mean \pm standard deviation or median and $25^{\text {th }}$ and $75^{\text {th }}$ percentiles. Comparisons between groups were performed by one way analysis of variance (ANOVA) followed by Bonferroni or Kruskal-Wallis followed by Dunn test (comparisons: SHR-C vs WKY and SHR-SPR vs SHR-C). Heart failure feature frequencies and mortality rate were assessed by the Goodman test. Statistical significance was accepted at $\mathrm{p}<0.05$.

\section{Results}

\section{Experimental groups and anatomical variables}

During the experimental period, WKY, SHR-C, and SHR-SPR groups presented mortality rates of $0 \%, 25 \%$ and $12.5 \%$, respectively ( $\mathrm{p}<0.05$ SHR-C vs WKY). The mortality rate in SHR-SPR was intermediate but did not statistically differ from SHR-C. Heart failure feature frequencies in the SHR groups are shown in Table 1. In rats surviving to the end of the experimental period, SHR-SPR presented a statistically lower frequency of right ventricular hypertrophy. No WKY rat presented any evidence of heart failure.

Blood pressure and anatomical data are presented in Table 2. Initial body weight did not differ between groups. Final body weight was lower in both SHR groups than WKY. Systolic blood pressure was higher in SHR groups than WKY and did not differ between SHR-SPR and SHR-C in both the initial and final period. Left ventricle in absolute and normalized to body weight and tibia length values were higher in SHR-C than WKY and did not differ between SHR-SPR and SHR-C. Absolute and normalized values of right ventricle and atria weight were higher in SHR-C than WKY and lower in SHR-SPR than SHR-C. Lung weight, lung weight-tobody weight ratio, and lung wet-to-dry weight ratio were higher in SHR-C than WKY and did not differ between SHR-SPR and SHR-C.

Table 1. Frequency of heart failure features in the spontaneously hypertensive rats

\begin{tabular}{|c|c|c|}
\hline \multirow[b]{2}{*}{ Variables } & \multicolumn{2}{|c|}{ Frequency (\%) } \\
\hline & $\begin{array}{c}\text { SHR-C } \\
(15)\end{array}$ & $\begin{array}{c}\text { SHR-SPR } \\
\text { (21) }\end{array}$ \\
\hline Pulmonary congestion & 80 & 67 \\
\hline Right ventricular hypertrophy & 47 & 0 \# \\
\hline
\end{tabular}


Table 2. Blood pressure and anatomic data

\begin{tabular}{|c|c|c|c|}
\hline Variables & $\begin{array}{c}\text { WKY } \\
(n=15)\end{array}$ & $\begin{array}{l}\text { SHR-C } \\
(n=15)\end{array}$ & $\begin{array}{c}\text { SHR-SPR } \\
(\mathrm{n}=21)\end{array}$ \\
\hline Initial BW (g) & $381 \pm 19$ & $390 \pm 21$ & $383 \pm 20$ \\
\hline Final BW (g) & $400 \pm 27$ & $356 \pm 40^{*}$ & $366 \pm 40$ \\
\hline Initial SBP (mmHg) & $111 \pm 09$ & $199 \pm 13^{*}$ & $190 \pm 21$ \\
\hline Final SBP (mmHg) & $113 \pm 12$ & $184 \pm 24^{*}$ & $197 \pm 22$ \\
\hline Tibia length $(\mathrm{cm})$ & $4.09 \pm 0.07$ & $4.25 \pm 0.09^{*}$ & $4.29 \pm 0.08$ \\
\hline LVW (g) & $0.76 \pm 0.04$ & $1.22 \pm 0.18^{*}$ & $1.18 \pm 0.15$ \\
\hline LVW/BW (g/kg) & $1.92 \pm 0.09$ & $3.42 \pm 0.35^{*}$ & $3.26 \pm 0.34$ \\
\hline LVW/tibia (mg/cm) & $187 \pm 10$ & $286 \pm 41^{*}$ & $274 \pm 37$ \\
\hline RVW (g) & $0.25 \pm 0.04$ & $0.31 \pm 0.08^{*}$ & $0.24 \pm 0.03^{\#}$ \\
\hline RVW/BW (g/kg) & $0.58 \pm 0.16$ & $0.82 \pm 0.33^{*}$ & $0.65 \pm 0.08^{\#}$ \\
\hline RVW/tibia (mg/cm) & $60.5 \pm 8.99$ & $73.1 \pm 19.4^{*}$ & $54.9 \pm 6.36^{\#}$ \\
\hline Atria (g) & $0.09 \pm 0.01$ & $0.15 \pm 0.05^{*}$ & $0.12 \pm 0.02^{\#}$ \\
\hline Atria/BW (g/kg) & $0.20 \pm 0.06$ & $0.41 \pm 0.16^{*}$ & $0.33 \pm 0.05^{\#}$ \\
\hline Atria/tibia $(\mathrm{mg} / \mathrm{cm})$ & $21.0 \pm 15.0$ & $36.2 \pm 11.0^{*}$ & $26.9 \pm 4.38^{\#}$ \\
\hline Lung (g) & $2.08 \pm 0.32$ & $3.22 \pm 0.72 *$ & $3.25 \pm 0.85$ \\
\hline Lung/BW (g/kg) & $5.27 \pm 1.11$ & $9.10 \pm 2.22^{*}$ & $9.00 \pm 2.53$ \\
\hline Lung wet/dry & $4.66 \pm 0.14$ & $5.47 \pm 0.47^{*}$ & $5.51 \pm 0.56$ \\
\hline
\end{tabular}

Data as mean \pm standard deviation. WKY: Wistar-Kyoto rats; SHR-C: spontaneously hypertensive rats without treatment; SHR-SPR: spontaneously hypertensive rats treated with spironolactone; BW: body weight; SBP: systolic blood pressure; LVW: left ventricle weight; RVW: right ventricle weight; tibia: tibia length; wet/dry: wet weight-todry weight ratio; *: p < 0.05 vs WKY; * $\mathrm{p}<0.05$ vs SHR-C; ANOVA and Bonferroni.

Table 3. Echocardiographic structural cardiac data

\begin{tabular}{lccc}
\hline \multicolumn{1}{c}{ Variables } & $\begin{array}{c}\text { WKY } \\
(\mathrm{n}=15)\end{array}$ & $\begin{array}{c}\text { SHR-C } \\
(\mathrm{n}=15)\end{array}$ & $\begin{array}{c}\text { SHR-SPR } \\
(\mathrm{n}=21)\end{array}$ \\
\hline HR (bpm) & $249 \pm 26$ & $317 \pm 42^{*}$ & $302 \pm 43$ \\
LVDD (mm) & $7.77 \pm 0.54$ & $7.63 \pm 0.97$ & $7.87 \pm 0.79$ \\
LVDD/BW (mm/kg) & $19.6(18.8-20.9)$ & $19.9(19.2-22.7)$ & $21.2(20.1-24.3)$ \\
LVSD (mm) & $3.03 \pm 0.65$ & $3.33 \pm 1.39$ & $3.16 \pm 1.00$ \\
LVPWT (mm) & $1.46 \pm 0.13$ & $1.76 \pm 0.14^{*}$ & $1.81 \pm 0.17$ \\
LVSWT (mm) & $1.51 \pm 0.12$ & $1.78 \pm 0.13^{*}$ & $1.84 \pm 0.18$ \\
AO (mm) & $4.07 \pm 0.25$ & $4.54 \pm 0.33^{*}$ & $4.53 \pm 0.43$ \\
LA (mm) & $5.81(5.46-6.04)$ & $6.11(5.67-8.11)^{*}$ & $6.94(6.64-7.27)$ \\
LA/BW (mm/g) & $14.9 \pm 2.17$ & $19.0 \pm 4.48^{*}$ & $19.2 \pm 2.56$ \\
LVM (g) & $0.81 \pm 0.14$ & $1.00 \pm 0.25^{*}$ & $1.10 \pm 0.27$ \\
LVMI (g/kg) & $2.07 \pm 0.30$ & $2.79 \pm 0.76^{*}$ & $3.07 \pm 0.75$ \\
RWT & $0.38 \pm 0.03$ & $0.47 \pm 0.06^{*}$ & $0.46 \pm 0.05$
\end{tabular}

Data as mean \pm standard deviation or median and $25^{\text {th }}$ and $75^{\text {th }}$ percentiles. WKY: Wistar-Kyoto rats; SHR-C: spontaneously hypertensive rats without treatment; SHR-SPR: spontaneously hypertensive rats treated with spironolactone. HR: heart rate; LVDD and LVSD: left ventricular (LV) diastolic and systolic diameters, respectively; BW: body weight; LVPWT: LV posterior wall thickness; LVSWT: LV septal wall thickness; AO: aorta diameter; LA: left atrial diameter; LVM: LV mass; LVMI: LV mass index; RWT: relative wall thickness. ${ }^{*}$ p<0.05 vs WKY; one way ANOVA and Bonferroni or Kruskal-Wallis and Dunn.

Hematoxylin and eosin-stained myocardial histological sections are shown in Figure 1. Myocyte cross-sectional area was greater in SHR-C than in WKY and SHR-SPR groups (WKY 388 \pm 80 ; SHR-C 533 \pm 94 ; SHR-SPR $393 \pm 58 \mu \mathrm{m}^{2}$; $\mathrm{p}<0.05$ ).

\section{Echocardiographic evaluation}

Echocardiogram performed at the beginning of the experiment did not show any differences between SHR-SPR and SHR-C groups (data not shown). Illustrative LV M-mode echocardiograms are shown in Figure 2. Final echocardiographic data are presented in Tables 3 and 4. Comparing to WKY, SHR-C presented increased heart rate, LV posterior and septal wall thickness, aorta diameter, left atrial diameter, LV mass, and relative wall thickness and 
Table 4. Echocardiographic left ventricular functional parameters

\begin{tabular}{lccc}
\hline \multicolumn{1}{c}{ Variables } & $\begin{array}{c}\text { WKY } \\
(\mathrm{n}=15)\end{array}$ & $\begin{array}{c}\text { SHR-C } \\
(\mathrm{n}=15)\end{array}$ & $\begin{array}{c}\text { SHR-SPR } \\
(\mathrm{n}=21)\end{array}$ \\
\hline EF & $0.94 \pm 0.07$ & $0.92 \pm 0.08$ & $0.94 \pm 0.08$ \\
MWFS (\%) & $35.0 \pm 4.10$ & $29.2 \pm 5.70^{*}$ & $29.5 \pm 4.99$ \\
PWSV (mm/s) & $30.2(26.7-34.1)$ & $33.0(31.1-37.1)$ & $29.6(28.5-32.2)$ \\
E-wave $(\mathrm{cm} / \mathrm{s})$ & $93.0(84.5-95.5)$ & $74.5(56.0-84.0)$ & $85.0(70.0-98.7)$ \\
A-wave $(\mathrm{cm} / \mathrm{s})$ & $46.0(43.0-49.0)$ & $63.5(39.0-93.0)$ & $64.5(47.5-107)$ \\
E/A & $2.06(1.76-2.16)$ & $0.81(0.64-2.15)$ & $1.27(0.75-1.81)$ \\
\hline
\end{tabular}

Data as mean \pm standard deviation or median and $25^{\text {th }}$ and $75^{\text {th }}$ percentiles. WKY: Wistar-Kyoto rats; SHR-C: spontaneously hypertensive rats without treatment; SHR-SPR: spontaneously hypertensive rats treated with spironolactone. EF: ejection fraction; MWFS: midwall fractional shortening; PWSV: posterior wall shortening velocity; E-wave and A-wave: early and late diastolic mitral inflow, respectively. ${ }^{*} \mathrm{p}<0.05 \mathrm{vs} \mathrm{WKY;}{ }^{\S}=0.076$; one way ANOVA and Bonferroni or Kruskal-Wallis and Dunn.

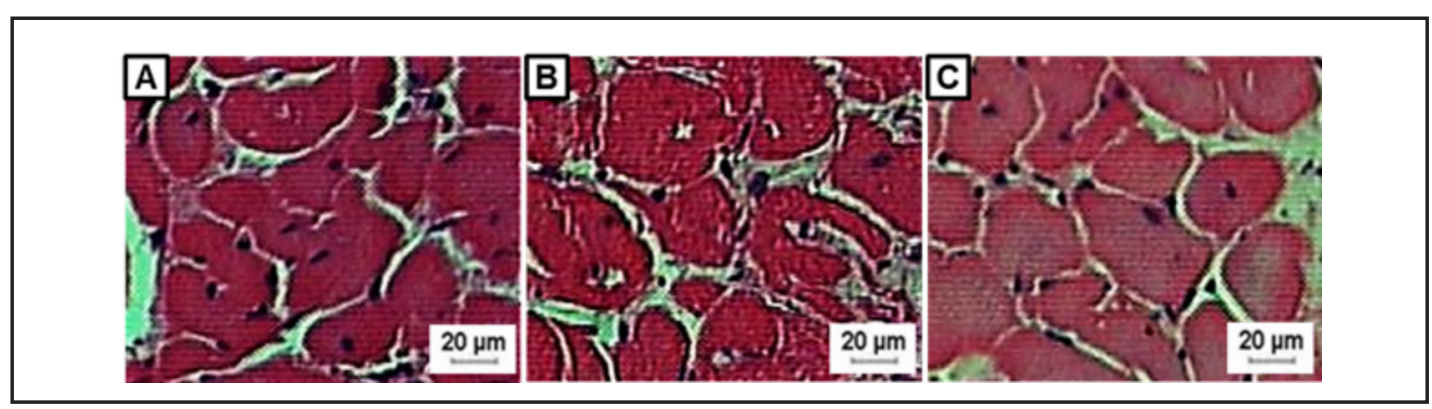

Fig. 1. Hematoxylin and eosin-stained myocardial histological sections. A: Wistar-Kyoto rats (WKY); B: spontaneously hypertensive rats without treatment (SHR-C); C: spontaneously hypertensive rats treated with spironolactone (SHR-SPR).

Fig. 2. Illustrative left ventricle M-mode echocardiograms. LVDD and LVSD: left ventricular (LV) diastolic and systolic diameters, respectively; PW: LV posterior wall; IVS: interventricular septum; WKY: Wistar-Kyoto rats; SHR-C: spontaneously hypertensive rats without treatment; SHR-SPR: spontaneously hypertensive rats treated with spironolactone.

decreased midwall fractional shortening. There were no differences between SHRSPR and SHR-C.

\section{Papillary muscle study}

Illustrative papillary muscle recordings during isometric contractions at extracellular calcium concentration of 1.25 $\mathrm{mM}$ are shown in Figure 3. Basal papillary muscle functional data are presented in Table 5. SHR-SPR presented higher peak of developed tension, $+\mathrm{dT} / \mathrm{dt}$, and $-\mathrm{dT} / \mathrm{dt}$ compared to SHR-C. Resting tension was higher in SHR-C than WKY and did not differ between SHR-SPR and SHR-C. After

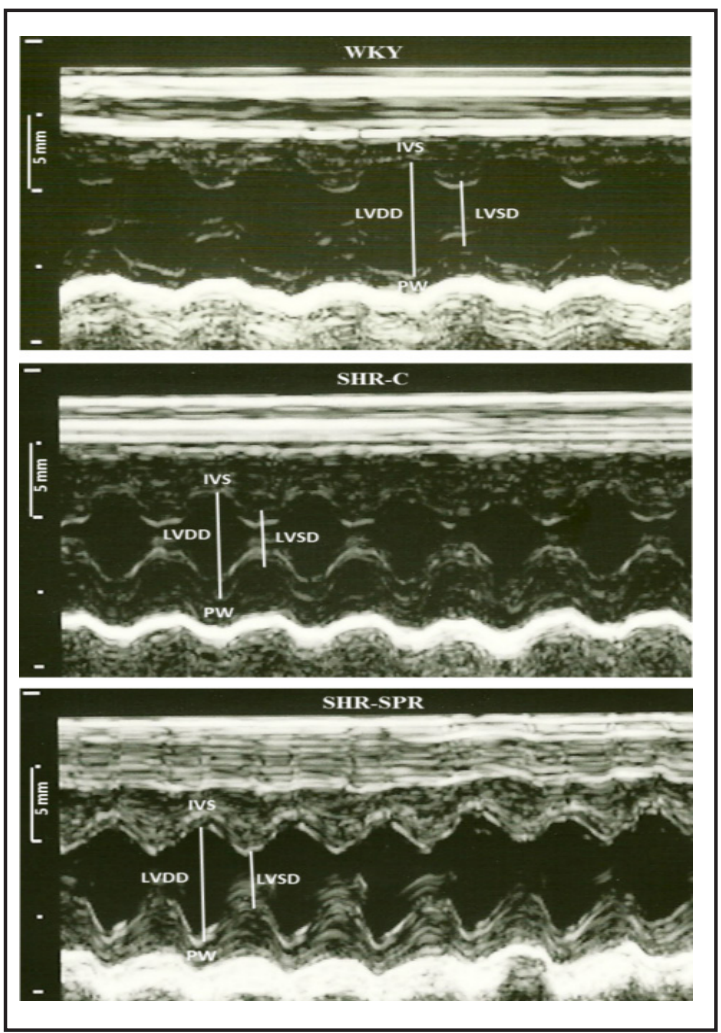


Fig. 3. Illustrative papillary muscle recordings during isometric contractions at extracellular calcium concentration of $1.25 \mathrm{mM}$. DT: peak of developed tension; RT: resting tension; WKY: Wistar-Kyoto rats; SHR-C: spontaneously hypertensive rats without treatment; SHR-SPR: spontaneously hypertensive rats treated with spironolactone.

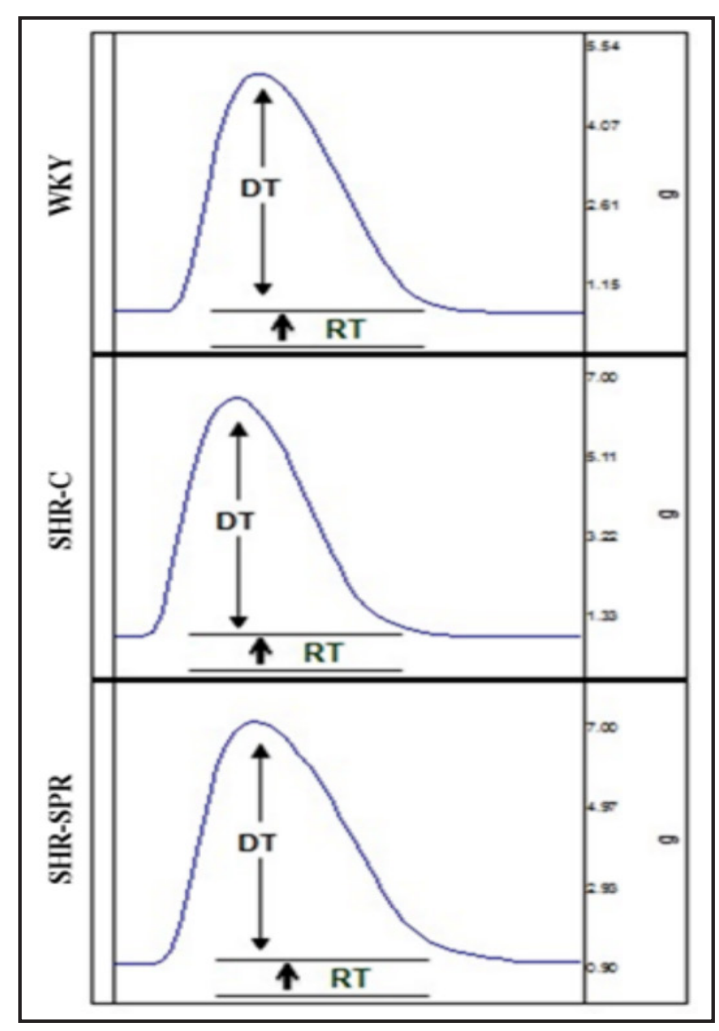

Table 5. Isolated papillary muscle basal data

\begin{tabular}{lccc}
\hline \multicolumn{1}{c}{ Variables } & $\begin{array}{c}\text { WKY } \\
(\mathrm{n}=11)\end{array}$ & $\begin{array}{c}\text { SHR-C } \\
(\mathrm{n}=12)\end{array}$ & $\begin{array}{c}\text { SHR-SPR } \\
(\mathrm{n}=19)\end{array}$ \\
\hline $\mathrm{DT}\left(\mathrm{g} / \mathrm{mm}^{2}\right)$ & $4.85 \pm 0.68$ & $5.22 \pm 1.64$ & $6.80 \pm 1.49^{\#}$ \\
$\mathrm{RT}\left(\mathrm{g} / \mathrm{mm}^{2}\right)$ & $0.58 \pm 0.15$ & $0.84 \pm 0.24^{*}$ & $1.00 \pm 0.18$ \\
TPT $(\mathrm{ms})$ & $208 \pm 16$ & $212 \pm 12$ & $204 \pm 14$ \\
$+\mathrm{dT} / \mathrm{dt}\left(\mathrm{g} / \mathrm{mm}^{2} / \mathrm{s}\right)$ & $44.7 \pm 6.82$ & $46.9 \pm 17.4$ & $61.0 \pm 17.4^{\#}$ \\
-dT $/ \mathrm{dt}\left(\mathrm{g} / \mathrm{mm}^{2} / \mathrm{s}\right)$ & $18.0(16.0-19.0)$ & $20.8(18.4-25.1)$ & $28.9(24.2-34.6)^{\#}$ \\
$\mathrm{CSA}\left(\mathrm{mm}^{2}\right)$ & $1.25 \pm 0.22$ & $1.17 \pm 0.30$ & $0.97 \pm 0.26$ \\
\hline
\end{tabular}

Data as mean \pm standard deviation or median and $25^{\text {th }}$ and $75^{\text {th }}$ percentiles. WKY: Wistar-Kyoto rats; SHR-C: spontaneously hypertensive rats without treatment; SHR-SPR: spontaneously hypertensive rats treated with spironolactone. DT: peak of developed tension; RT: resting tension; TPT: time to peak of tension; +dT/dt: maximum rate of tension development; - $\mathrm{dT} / \mathrm{dt}$ : maximum rate of tension decline; CSA: cross-sectional area. * $\mathrm{p}<0.05$ vs WKY; $\# \mathrm{p}<0.05$ vs. SHR-C; one way ANOVA and Bonferroni or Kruskal-Wallis and Dunn.

inotropic stimulation, peak of developed tension remained higher in SHR-SPR than SHR-C and did not differ between SHR-C and WKY (Fig. 4).

\section{Biochemical analysis}

Serum concentrations of sodium (WKY 152 \pm 3.58 ; SHR-C 155 \pm 4.55 ; SHR-SPR $155 \pm 1.96$ $\mathrm{mEq} / \mathrm{L}$ ), potassium (WKY 5.94 \pm 0.23 ; SHR-C 5.93 \pm 0.46 ; SHR-SPR 6.13 $\pm 0.46 \mathrm{mEq} / \mathrm{L}$ ), magnesium (WKY 2.18 \pm 0.16 ; SHR-C 2.48 \pm 0.43 ; SHR-SPR 2.34 \pm 0.12 ), and creatinine (WKY $0.55 \pm 0.01$; SHR-C 0.61 \pm 0.08 ; SHR-SPR 0.60 \pm 0.06 ) did not differ between groups.

\section{Myocardial fibrosis}

Total collagen concentration was higher in SHR-C than WKY and SHR-SPR (WKY $1.06 \pm 0.34$; SHR-C 1.85 \pm 0.63 ; SHR-SPR $1.28 \pm 0.39 \mu \mathrm{g} / \mathrm{mg}$ wet tissue; $\mathrm{p}<0.05)$. Soluble collagen did not differ between groups (WKY 1.59 \pm 0.16 ; SHR-C 1.51 \pm 0.15 ; SHR-SPR $1.61 \pm 0.19 \mu \mathrm{g} /$ $\mathrm{mg}$ wet tissue; $\mathrm{p}>0.05$ ). Type 3 collagen expression was lower in SHR-C than WKY and did 
Fig. 4. Peak of developed tension (DT) after inotropic stimulation with post-rest contraction (a), extracellular calcium concentration increase (b), and $\beta$-adrenergic agonist isoproterenol addition to the nutrient solution (c); WKY: WistarKyoto rats; SHR-C: spontaneously hypertensive rats without treatment; SHR-SPR: spontaneously hypertensive rats treated with spironolactone; \# $\mathrm{p}<0.05$ SHR-SPR vs SHR-C; ANOVA and Bonferroni. a

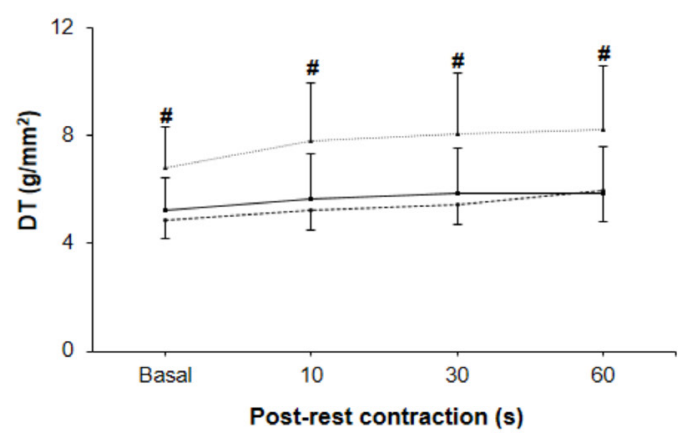

b

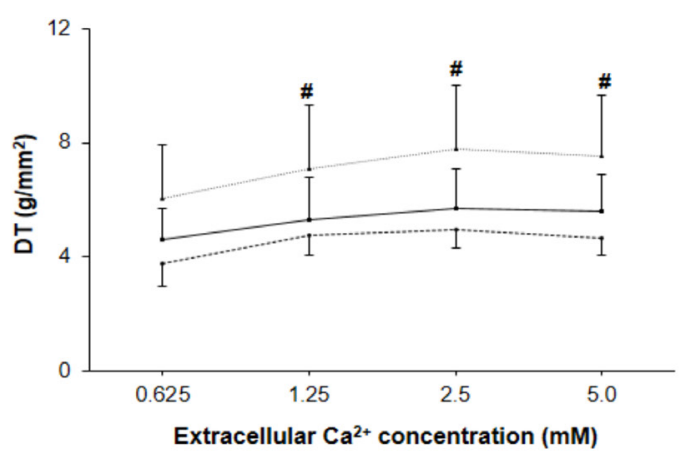

C

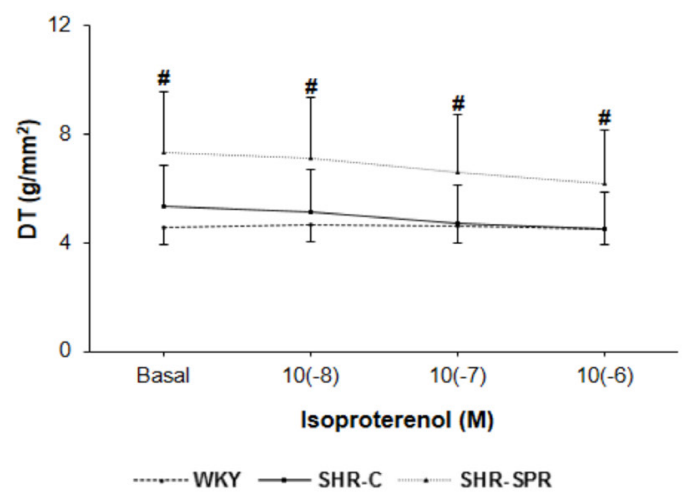

not differ between SHR-SPR and SHR-C. There was a trend for type 1 collagen to be higher in SHR-C ( $\mathrm{p}=0.07)$; lysyl oxidase expression did not differ between groups (Fig. 5).

\section{Discussion}

In this study we evaluated the effects of early administration of the aldosterone blocker spironolactone on cardiac structure and function and extracellular matrix remodeling in spontaneously hypertensive rats.

In a previous study, we showed that chronic treatment of SHR with spironolactone initiated at 16 months of age reduces mortality without changing cardiac structures and function [23], which allowed us to develop the hypothesis that spironolactone reduces mortality by decreasing arrhythmia. Furthermore, as treatment was started later during pressure-overload cardiac remodeling, it was probable that rats had already presented advanced degrees of left cardiac chambers hypertrophy and fibrosis, thus preventing a reverse remodelling process. This is therefore the first study to evaluate the effects of aldosterone blockade during the transition from compensated left ventricular hypertrophy to heart failure. We started spironolactone treatment at 13 months old. 

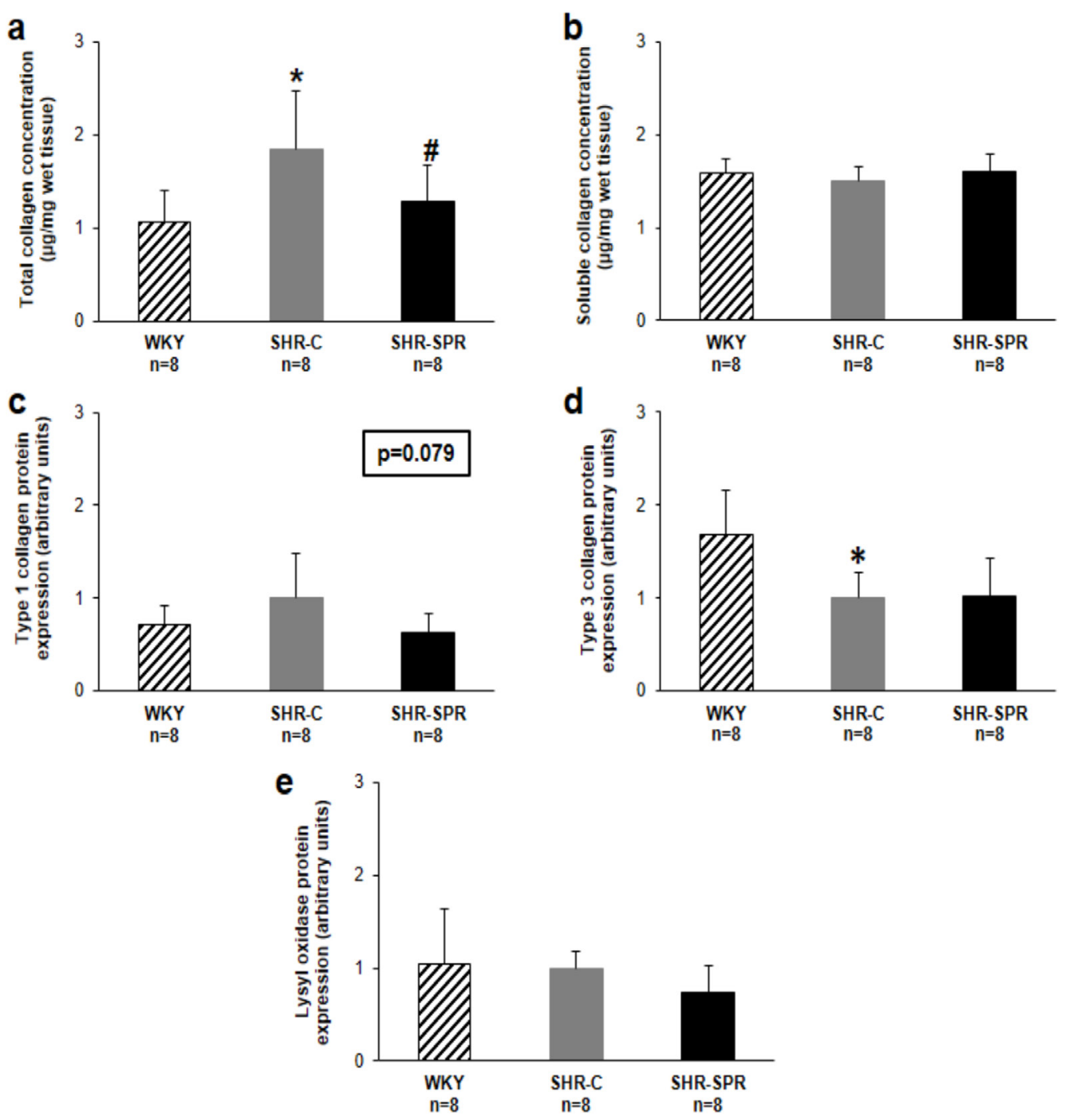

Fig. 5. Total (a) and soluble (b) collagen concentration; protein expression of type I (c) and type III (d) collagen and lysyl oxidase (e); WKY: Wistar-Kyoto rats; SHR-C: spontaneously hypertensive rats without treatment; SHR-SPR: spontaneously hypertensive rats treated with spironolactone; * p $<0.05$ vs WKY; \# p<0.05 vs SHR-C; ANOVA and Bonferroni.

The spontaneously hypertensive rat is a well-established model of genetic hypertension $[3,22]$. At one month old, arterial hypertension starts to increase stimulating left ventricular hypertrophy, which often preserves cardiac performance despite the elevated systemic arterial pressure $[42,43]$. During compensated cardiac hypertrophy, myocardial function is improved in SHR when compared to normotensive WKY rats [3, 25, 44]. If pressure overload is sustained, cardiac decompensation ensues, usually at 18-22 months of age. After developing heart failure, rats evolve to death within two to four weeks [2, 3].

At the beginning of this study, SHR presented no clinical features of heart failure such as tachypnea/labored respiration or body weight loss [28]. The initial echocardiogram showed no differences between SHR-C and SHR-SPR thus assuring homogeneity between SHR groups. Treatment with spironolactone did not change arterial blood pressure. This result is in accordance with other authors showing that the spironolactone dose used in this study can induce beneficial cardiac effects without modifications in blood pressure $[14,23$, $45,46]$. As blood pressure remained unchanged, it was possible to exclude the influence of hemodynamic effects on our results. 
As final body weight was lower in the SHR groups, anatomic variables were normalized to both body weight and tibia length. In SHR-C, left and right ventricle and atria weight, in absolute and normalized values, were greater than in the WKY group, showing hypertrophy of cardiac chambers. Spironolactone treatment reduced atria and right ventricle weight compared to SHR-C. The frequency of pulmonary congestion in surviving rats did not differ between SHR-SPR and SHR-C. However, right ventricular hypertrophy was significantly less frequent in SHR-SPR than SHR-C. Right ventricular hypertrophy usually develops later than lung congestion and is considered a good marker of heart failure in rats [2, 28]. Therefore, we conclude that early spironolactone administration reduced the rate of heart failure development without changing arterial blood pressure in SHR.

Final echocardiogram showed that SHR-C presented dilated left atrium, concentric left ventricular hypertrophy, characterized by increased LV mass, LV wall thicknesses, and relative wall thickness, and systolic dysfunction characterized by the decreased midwall fractional shortening. The trend for E/A ratio to be lower in SHR-C suggests a mild degree of diastolic dysfunction in SHR-C compared to WKY. The greatly increased arterial blood pressure in both SHR groups could explain why these animals presented heart failure features in the absence of advanced echocardiographic changes. In rats with myocardial infarction-induced heart failure, in which blood pressure is preserved or reduced, important alterations in structural and functional echocardiographic parameters can be found [28]. Spironolactone treatment did not change echocardiographic parameters. Similar results have been observed in SHR treated with short-term spironolactone [46]. In the RALES [17], EPHESUS [16], and EMPHASIS-HF [18] clinical multicenter trials, cardiac structure and function were not evaluated after treatment with aldosterone blockers.

Papillary muscle preparations allow the evaluation of myocardial function without the influence of cardiac load. In this study, the only myocardial functional parameter displaying a difference at basal conditions between SHR-C and WKY was increased resting tension in SHR-C. These results are usually observed in SHRs. When they are compared to normotensive WKY rats, they usually present enhanced isolated papillary muscle performance up to 18 months of age. As they age, SHRs present unchanged function, and finally a depressed myocardial function [3, 25, 44]. Our SHR-SPR presented improved myocardial systolic function, characterized by increased developed tension and $+\mathrm{dT} / \mathrm{dt}$, and improved diastolic function, characterized by higher -dT/dt values compared to SHR-C. After positive inotropic stimulation, developed tension remained higher in SHR-SPR than SHR-C, and was unchanged between SHR-C and WKY, showing that spironolactone treatment preserved myocardial contractile reserve. We can then conclude that aldosterone blockade enhances myocardial function by improving in vitro systolic and diastolic function. This result diverges from that observed during in vivo cardiac functional evaluation. It is probable that the in vivo unchanged LV function was caused by the highly increased afterload, which prevented changes in myocardial function from being detected by echocardiogram.

Long-term pressure overload-induced cardiac remodeling mainly consists of cardiomyocyte hypertrophy and changes in phenotype and amount of myocardial collagen. We therefore evaluated the degree of myocyte hypertrophy and myocardial fibrosis. Despite unchanged left ventricle weight, myocyte cross-sectional area was lower in SHRSPR than SHR-C, suggesting that hypertrophy was attenuated by spironolactone treatment independent of elevated systemic arterial pressure. Aldosterone can directly stimulate myocyte growth in isolated neonatal rat myocytes showing that it can induce hypertrophy independently of it inducing renal sodium and water retention [6].

Aldosterone has long been shown to induce myocardial interstitial and perivascular fibrosis and aldosterone blockade can prevent or attenuate collagen synthesis in several models of myocardial injury $[14,47,48]$. Fibrillar collagen types I and III are the predominant components of cardiac extracellular matrix [49]. Mechanical cardiac properties are not only modulated by the amount of collagen in myocardium but also by the collagen crosslinking. Tissue containing predominantly type I collagen is stiffer than tissue composed of greater concentrations of type III fibers $[26,50]$. In this study, the trend towards mild diastolic 


\section{Cellular Physiology Cell Physiol Biochem 2015;36:1453-1466 \begin{tabular}{l|l|l} 
DOI: 10.1159/000430310 & C 2015 S. Karger AG, Basel
\end{tabular} \begin{tabular}{l|l} 
and Biochemistry Publisned online: July 06,2015 & www.karger.com/cpb
\end{tabular}

dysfunction in SHR-C compared to WKY can be explained by increased total myocardial collagen concentration and decreased type 3 collagen expression. This result agrees with previous studies on aging SHR showing that heart failure development is associated with marked myocardial fibrosis and impaired contractile function, which suggests that fibrosis or changes in connective tissue response are important during the transition from compensated hypertrophy to failure [25]. Also in normotensive heart failure, serum levels of markers of cardiac fibrosis synthesis are associated with poor outcome. Zannad et al. [51] showed that the morbidity and mortality benefit from aldosterone blocker is predominant in patients with the highest serum levels of markers of cardiac fibrosis synthesis, which are decreased during spironolactone therapy.

The improved systolic myocardial function seen in SHR-SPR was combined with a reduced total collagen concentration and a trend towards decreased type I collagen expression compared to SHR-C. Therefore, myocardial fibrosis, by restricting myofibrillar motion [25], may have contributed to the impaired cardiac function. Type 3 collagen and lysyl oxidase expression and soluble collagen concentration were not changed by spironolactone treatment. In spontaneously rats with hypertensive heart failure, plasma aldosterone concentration has been shown to increase progressively from 13 month-old reaching a level approximately $60 \%$ higher after 12 weeks [46]. We have not identified any studies in literature evaluating the effects of early spironolactone treatment alone in SHR during the transition from compensated hypertrophy to decompensated heart failure. Munoz-Pacheco et al. [24] treated two-month old SHR with eplerenone plus conventional heart failure therapy for 20 months and observed structural and functional cardiac improvement, delayed heart failure progression, and matricellular protein expression normalization. As previously reported, aldosterone can induce several deleterious effects on the cardiovascular system. Thus, additional studies are needed to evaluate other potential mechanisms involved in spironolactone-induced systolic myocardial function improvement in pressure overloaded hearts.

In conclusion, early administration of spironolactone decreases the frequency of heart failure development by improving myocardial systolic and diastolic function and attenuating myocardial hypertrophy and fibrosis in spontaneously hypertensive rats.

\section{Disclosure Statement}

No conflict of interest declared.

\section{Acknowledgements}

We are grateful to Jose Carlos Georgette and Mario Batista Bruno for their technical assistance and Colin Edward Knaggs for English editing. Financial support was provided by CNPq (306857/2012-0, 306845/2012-1, and 480829/2013-6), FAPESP (2009/54506-7, 2009/54407-9, and 2009/54102-3), and PROPe, UNESP.

\section{References}

$\longrightarrow$ Go AS, Mozaffarian D, Roger VL, Benjamin EJ, Berry JD, Blaha MJ, Dai S, Ford ES, Fox CS, Franco S, Fullerton HJ, Gillespie C, Hailpern SM, J.A. H, Howard VJ, Huffman MD, Judd SE, Kissela BM, Kittner SJ, Lackland DT, Lichtman JH, Lisabeth LD, Mackey RH, Magid DJ, Marcus GM, Marelli A, Matchar DB, McGuire DK, Mohler ER, Moy CS, Mussolino ME, Neumar RW, Nichol G, Pandey DK, Paynter NP, Reeves MJ, Sorlie PD, Stein J, Towfighi A, Turan TN, Virani SS, Wong ND, Woo D, Turner MB: Heart disease and stroke statistics-2014 update: A report from the american heart association. Circulation 2014;129:e28-e292.

-2 Bing OHL, Brooks WW, Robinson KG, Slawsky MT, Hayes JA, Litwin SE, Sen S, Conrad CH: The spontaneously hypertensive rat as a model of the transition from compensated left ventricular hypertrophy to failure. J Mol Cell Cardiol 1995;27: 383-396. 


\section{Cellular Physiology Cell Physiol Biochem 2015;36:1453-1466 \begin{tabular}{l|l|l} 
DOI: 10.1159/000430310 & C 2015 S. Karger AG, Basel
\end{tabular} and Biochemistry Publisnea onine: July vo, 2015 www.karger.com/cpb \\ Cezar et al.: Spironolactone in Hypertensive Rats}

3 Cicogna AC, Robinson KG, Conrad CH, Singh K, Squire R, Okoshi MP, Bing OHL: Direct effects of colchicine on myocardial function. Studies in hypertrophied and failing spontaneously hypertensive rats. Hypertension 1999;33:60-65.

4 Messaoudi S, Azibani F, Delcayre C, Jaisser F. Aldosterone, mineralocorticoid receptor, and heart failure: Mol Cell Endocrinol 2012;350:266-272.

5 Mihailidou AS. Aldosterone in heart disease. Curr Hypertens Rep. 2012;14:125-129.

6 Okoshi MP, Yan X, Okoshi K, Nakayama M, Schuldt AJT, O'Connell T, Simpson PC, Lorell BH: Aldosterone directly stimulates cardiac myocyte hypertrophy. J Card Fail 2004;10:511-518.

$\rightarrow 7$ Nolly MB, Caldiz CI, Yeves AM, Villa-Abrille MC, Morgan PE, Amado Mondaca N, Portiansky EL, Chiappe de Cingolani GE, Cingolani HE, Ennis IL: The signaling pathway for aldosterone-induced mitochondrial production of superoxide anion in the myocardium. J Mol Cell Cardiol 2014; 67:60-68.

-8 Cheema Y, Zhao W, Zhao T, Khan MU, Green KD, Ahokas RA, Gerling IC, Bhattacharya SK, Weber KT: Reverse remodeling and recovery from cachexia in rats with aldosteronism. Am J Physiol Heart Circ Physiol 2012;303:H486-H495.

-9 Mano A, Tatsumi T, Shiraishi J, Keira N, Nomura T, Takeda M, Nishikawa S, Yamanaka S, Matoba S, Kobara M, Tanaka H, Shirayama T, Takamatsu T, Nozawa Y, Matsubara H: Aldosterone directly induces myocyte apoptosis through calcineurin-dependent pathways. Circulation 2004;110:317-323.

10 Struthers AD, MacDonald TM: Review of aldosterone- and angiotensin ii-induced target organ damage and prevention. Cardiovasc Res 2004;61:663-670.

11 Fraccarollo D, Galuppo P, Schraut S, Kneitz S, Rooijen N, Ertl G, Bauersachs J: Immediate mineralocorticoid receptor blockade improves myocardial infarct healing by modulation of the inflammatory response. Hypertension 2008;51:905-914.

12 Kuster GM, Kotlyar E, Rude MK, Siwik DA, Liao R, Colucci WS, Sam F: Mineralocorticoid receptor inhibition ameliorates the transition to myocardial failure and decreases oxidative stress and inflammation in mice with chronic pressure overload. Circulation 2005;111:420-427.

13 Martin-Fernandez B, de Las Heras N, Miana M, Ballesteros S, Valero-Munoz M, Vassallo D, Davel AP, Rossoni LV, Cachofeiro V, Lahera V: Spironolactone prevents alterations associated with cardiac hypertrophy produced by isoproterenol in rats: Involvement of sgk-1. Exp Physiol 2012;97:710-718.

14 Veliotes DG, Norton GR, Correia RJ, Strijdom H, Badenhorst D, Brooksbank R, Woodiwiss AJ: Impact of aldosterone receptor blockade on the deleterious cardiac effects of adrenergic activation in hypertensive rats. J Cardiovasc Pharmacol 2010;56:203-211.

15 Kobayashi N, Yoshida K, Nakano S, Ohno T, Honda T, Tsubokou Y, Matsuoka H: Cardioprotective mechanisms of eplerenone on cardiac performance and remodeling in failing rat hearts. Hypertension 2006;47:671-679.

16 Pitt B, Remme W, Zannad F, Neaton J, Martinez F, Roniker B, Bittman R, Hurley S, Kleiman J, Gatlin M: Eplerenone, a selective aldosterone blocker, in patients with left ventricular dysfunction after myocardial infarction. N Engl J Med 2003;348:1309-1321.

17 Pitt B, Zannad F, Remme WJ, Cody R, Castaigne A, Perez A, Palensky J, Wittes J: The effect of spironolactone on morbidity and mortality in patients with severe heart failure. Randomized aldactone evaluation study (rales) investigators. N Engl J Med 1999;341:709-717.

-18 Zannad F, McMurray JV, Krum H, van Veldhuisen DJ, Swedberg K, Shi H, Vincent J, Pocock SJ, Pitt B: Eplerenone in patients with systolic heart failure and mild symptoms. Emphasis-hf study group. N Engl J Med 2011;364:11-21.

19 Vizzardi E, Nodari S, Caretta G, D'Aloia A, Pezzali N, Faden G, Lombardi C, Raddino R, Metra M, Dei Cas L: Effects of spironolactone on long-term mortality and morbidity in patients with heart failure and mild or no symptoms. Am J Med Sci 2014;347:271-276.

20 Pitt B, Pfeffer MA, Assmann SF, Boineau R, Anand IS, Claggett B, Clausell N, Desai AS, Diaz R, Fleg JL, Gordeev I, Harty B, Heitner JF, Kenwood CT, Lewis EF, O'Meara E, Probstfield JL, Shaburishvili T, Shah SJ, Solomon SD, Sweitzer NK, Yang S, McKinlay SM: Spironolactone for heart failure with preserved ejection fraction. N Engl J Med 2014;370:1383-1392.

-21 Edelmann F, Wachter R, Schmidt AG, Kraigher-Krainer E, Colantonio C, Kamke W, Duvinage A, Stahrenberg R, Durstewitz K, Löffler M, Düngen HD, Tschöpe C, Herrmann-Lingen C, Halle M, Hasenfuss G, Gelbrich G, Pieske B: Effect of spironolactone on diastolic function and exercise capacity in patients with heart failure with preserved ejection fraction: The aldo-dhf randomized controlled trial. JAMA 2013;309:781-791. 


\section{Cellular Physiology Cell Physiol Biochem 2015;36:1453-1466

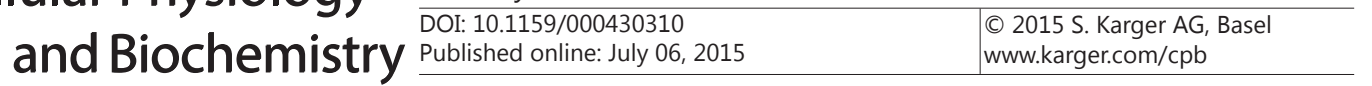 \\ Cezar et al.: Spironolactone in Hypertensive Rats}

22 Damatto RL, Martinez PF, Lima AR, Cezar MD, Campos DH, Oliveira SAJ, Guizoni DM, Bonomo C, Nakatani BT, Dal Pai Silva M, Carvalho RF, Okoshi K, Okoshi MP: Heart failure-induced skeletal myopathy in spontaneously hypertensive rats. Int J Cardiol 2013;167:698-703.

23 Cezar MD, Damatto RL, Martinez PF, Lima AR, Campos DH, Rosa CM, Guizoni DM, Bonomo C, Cicogna AC, Gimenes R, Pagan LU, Okoshi MP, Okoshi K: Aldosterone blockade reduces mortality without changing cardiac remodeling in spontaneously hypertensive rats. Cell Physiol Biochem 2013;32:1275-1287.

-24 Munoz-Pacheco P, Ortega-Hernandez A, Caro-Vadillo A, Casanueva-Eliceiry S, Aragoncillo P, Egido J, Fernandez-Cruz A, Gomez-Garre D: Eplerenone enhances cardioprotective effects of standard heart failure therapy through matricellular proteins in hypertensive heart failure. J Hypertens 2013;31:2309-2318.

25 Conrad CH, Brooks WW, Hayes JA, Sen S, Robinson KG, Bing OHL: Myocardial fibrosis and stiffness with hypertrophy and heart failure in the spontaneously hypertensive rat. Circulation 1995;91:161-170.

-26 Brower GL, Gardner JD, Forman MF, Murray DB, Voloshenyuk T, Levick SP, Janicki JS: The relationship between myocardial extracellular matrix remodeling and ventricular function. Eur J Cardiothorac Surg. 2006;30:604-610.

-27 Mukherjee D, Sen S. Collagen phenotypes during development and regression of myocardial hypertrophy in spontaneously hypertensive rats. Circ Res 1990;67:1474-1480.

28 Martinez PF, Okoshi K, Zornoff LA, Oliveira SAJ, Campos DH, Lima AR, Damatto RL, Cezar MD, Bonomo C, Guizoni DM, Padovani CR, Cicogna AC, Okoshi MP: Echocardiographic detection of congestive heart failure in postinfarction rats. J Appl Physiol 2011;111:543-551.

-29 Lima AR, Martinez PF, Okoshi K, Guizoni DM, Zornoff LA, Campos DH, Oliveira SAJ, Bonomo C, Pai-Silva MD, Okoshi MP: Myostatin and follistatin expression in skeletal muscles of rats with chronic heart failure. Int J Exp Path 2010;91:54-62.

-30 Okoshi K, Matsubara LS, Okoshi MP, Cicogna AC, Fioretto JR, Padovani CR, Aragon FF, Matsubara BB: Food restriction-induced myocardial dysfunction demonstrated by the combination of in vivo and in vitro studies. Nutr Res 2002;22:1353-1364.

-31 Okoshi K, Fioretto JR, Okoshi MP, Cicogna AC, Aragon FF, Matsubara LS, Matsubara BB: Food restriction induces in vivo ventricular dysfunction in spontaneously hypertensive rats without impairment of in vitro myocardial contractility. Braz J Med Biol Res 2004;37:607-613.

32 Lima AR, Martinez PF, Damatto RL, Cezar MD, Guizoni DM, Bonomo C, Oliveira SA Jr, Dal-Pai Silva M, Zornoff LA, Okoshi K, Okoshi MP: Heart failure-induced diaphragm myopathy. Cell Physiol Biochem 2014;34:333345.

33 Lang RM, Bierig M, Devereux RB, Flachskampf FA, Foster E, Pellikka PA, Picard MH, Roman MJ, Seward J, Shanewise JS, Solomon SD, Spencer KT, Sutton MSJ, Stewart WJ: Recommendations for chamber quantification: A report from the american society of echocardiography's guidelines and standards committee and the chamber quantification writing group, developed in conjunction with the european association of echocardiography, a branch of the european society of cardiology. J Am Soc Echocardiogr 2005;18:1440-1463.

-34 Okoshi MP, Okoshi K, Pai VD, Pai-Silva MD, Matsubara LS, Cicogna AC: Mechanical, biochemical, and morphological changes in the heart from chronic food restricted rats. Can J Physiol Pharmacol 2001;79:754-760.

-35 Cicogna AC, Padovani CR, Okoshi K, Matsubara LS, Aragon FF, Okoshi MP: The influence of temporal food restriction on the performance of isolated cardiac muscle. Nutr Res 2001;21:639-648.

-36 Gut AL, Okoshi MP, Padovani CR, Aragon FF, Cicogna AC: Myocardial dysfunction induced by food restriction is related to calcium cycling and beta-adrenergic system changes. Nutr Res 2003;23:911-919.

37 Fioretto JR, Queiroz SS, Padovani CR, Matsubara LS, Okoshi K, Matsubara BB: Ventricular remodeling and diastolic myocardial dysfunction in rats submitted to protein-calorie malnutrition. Am J Physiol 2002;282:H1327-H1333.

-38 Yan X, Schuldt AJ, Price RL, Amende I, Liu FF, Okoshi K, Ho KK, Pope AJ, Borg TK, Lorell BH, Morgan JP: Pressure overload-induced hypertrophy in transgenic mice selectively overexpressing at 2 receptors in ventricular myocytes. Am J Physiol Heart Circ Physiol 2008;294:1274-1281.

-39 Nascimento AF, Luvizotto RA, Leopoldo AS, Lima-Leopoldo AP, Seiva FR, Justulin LAJ, Silva MD, Okoshi K, Wang XD, Cicogna AC: Long-term high-fat diet-induced obesity decreases the cardiac leptin receptor withou apparent lipotoxicity. Life Sci 2011;88:1031-1038. 


\section{Cellular Physiology Cell Physiol Biochem 2015;36:1453-1466 \begin{tabular}{l|l} 
DOI: 10.1159/000430310 & \\
and Biochemistry & 2015 S. Karger AG, Basel
\end{tabular} www.karger.com/cpb \\ Cezar et al.: Spironolactone in Hypertensive Rats}

40 Alesutan I, Feger M, Pakladok T, Mia S, Ahmed MS, Voelkl J, Lang F: 25-Hydroxyvitamin D3 1- $\alpha$-hydroxylasedependent stimulation of renal klotho expression by spironolactone. Kidney Blood Press Res 2013;37:475487.

41 Chen X, Cai J, Zhou X, Chen L, Gong Y, Gao Z, Zhang H, Huang W, Zhou H: Protective effect of spironolactone on endothelial-to-mesenchymal transition in HUVECs via notch pathway. Cell Physiol Biochem 2015;36:191-200.

42 Cicogna AC, Padovani CR, Okoshi K, Aragon FF, Okoshi MP: Myocardial function during chronic food restriction in isolated hypertrophied cardiac muscle. Am J Med Sci 2000;320:244-248.

-43 Okoshi MP, Okoshi K, Matsubara LS, Pai-Silva MD, Gut AL, Padovani CR, Pai VD, Cicogna AC: Myocardial remodeling and dysfunction are induced by chronic food restriction in spontaneously hypertensive rats. Nutr Res 2006;26:567-572.

$\checkmark 44$ Bing OHL, Wiegner AW, Brooks WW, Fishbein MC, Pfeffer JM: Papillary muscle structure-function relations in the aging spontaneously hypertensive rat. Clin Exper Hyper-Theory and Practice 1988;10:37-58.

45 Baldo MP, Forechi L, Morra EA, Zaniqueli D, Machado RC, Lunz W, Rodrigues SL, Mill JG: Long-term use of low-dose spironolactone in spontaneously hypertensive rats: Effects on the left ventricular hypertrophy and stiffness. Pharmacol Rep 2011;63:975-982.

46 Kambara A, Holycross BJ, Wung P, Schanbacher B, Ghosh S, McCune SA, Bauer JA, Kwiatkowski P: Combined effects of low-dose oral spironolactone and captopril therapy in a rat model of spontaneous hypertension and heart failure. J Cardiovasc Pharmacol 2003;41:830-837.

-47 Vizzardi E, Regazzoni V, Caretta G, Gavazzoni M, Sciatti E, Bonadei I, Trichaki E, Raddino R, Metra M: Mineralocorticoid receptor antagonist in heart failure: past, present and future perspectives. IJC Heart \& Vessels 2014;3:6-14.

48 MacFadyen RJ, Barr CS, Struthers AD: Aldosterone blockade reduces vascular collagen turnover, improves heart rate variability and reduces early morning rise in heart rate in heart failure patients. Cardiovasc Res 1997;35:30-34.

-49 Fan D, Takawale A, Lee J, Kassiri Z. Cardiac fibroblasts, fibrosis and extracellular matrix remodeling in heart disease. Fibrogenesis Tissue Repair 2012;5:5-15.

50 Lopez B, Gonzalez A, Hermida N, Valencia F, de Teresa E, Diez J: Role of lysyl oxidase in myocardial fibrosis: From basic science to clinical aspects. Am J Physiol Heart Circ Physiol 2010;299:H1-H9.

51 Zannad F, Alla F, Dousset B, Perez A, Pitt B: Limitation of excessive extracellular matrix turnover may contribute to survival benefit of spironolactone therapy in patients with congestive heart failure: insights from the Randomized Aldactone Evaluation Study (RALES). Circulation 2000;102:2700-2706. 